\title{
Nonreversible enhanced crystallization of olefin block copolymer induced by pre-shearing
}

\author{
Jiashu Fan, Qinglong Zhang, Dingding Hu, Jiachun Feng*
}

State Key Laboratory of Molecular Engineering of Polymers, Collaborative Innovation Center of Polymers and Polymer Composite Materials, Department of Macromolecular Science, Fudan University, Shanghai 200433, P. R. China.

*jcfeng@fudan.edu.cn. Tel: 86 (21) 6564 3735. Fax: +86- 21-6564 0293. 


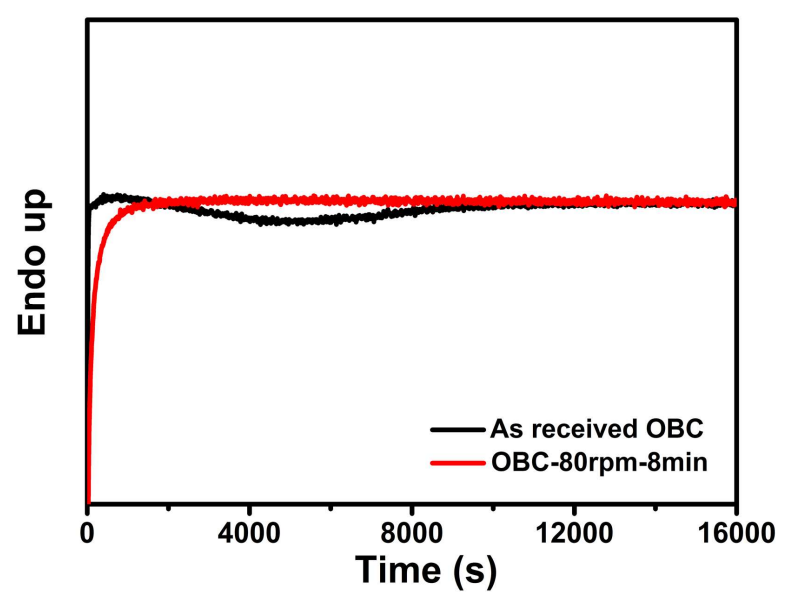

Figure S1. Isothermal crystallization curves of as received OBC and OBC-80rpm-8min at 115 ${ }^{\circ} \mathrm{C}$.

To better compare the crystallization ability of sheared $\mathrm{OBC}$ with that of as received $\mathrm{OBC}$, the isothermal crystallization of both samples was also performed at $115{ }^{\circ} \mathrm{C}$, although integrated isothermal crystallization curve cannot be achieved for OBC-80 rpm-8min. The results were presented in Figure S1. It can be observed that the time that as received OBC needs to complete crystallization was about $200 \mathrm{~min}$. For the reason that $115{ }^{\circ} \mathrm{C}$ was too low for the isothermal crystallization of OBC-80rpm-8min, the sheared sample already began to crystallize before cooling to $115^{\circ} \mathrm{C}$ which led to the incomplete crystallization curve of OBC-80rpm-8min. When reaching $115{ }^{\circ} \mathrm{C}$, OBC-80rpm-8min took only $4-5$ min to complete crystallization, which was much quicker than that of as received sample. Therefore, the conclusion that the crystallization ability of $\mathrm{OBC}$ was largely enhanced by shear can also be well supported by the isothermal crystallization results. 


\section{Determination of the ideal first $T_{s}$ of as-received $O B C$}

(a)

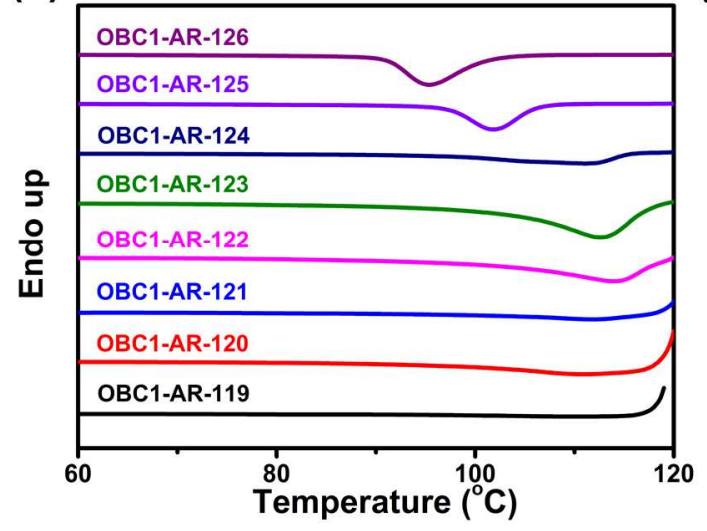

(b)

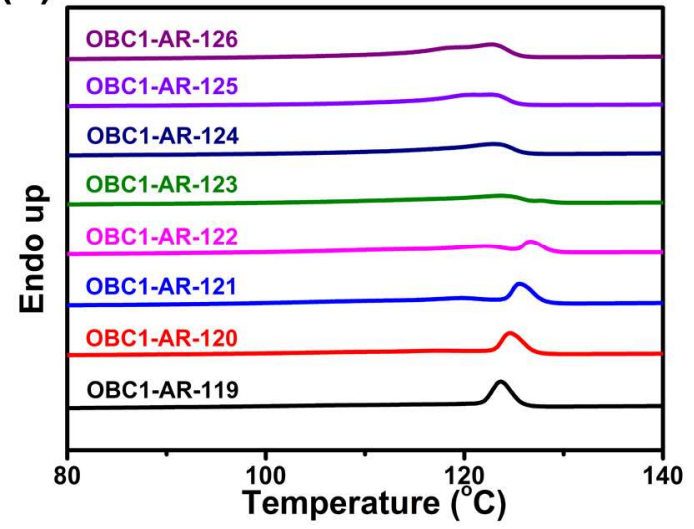

Figure S2. DSC cooling and heating curves after self-nucleation at the indicated $\mathrm{T}_{\mathrm{s}}$ temperatures for as-received $\mathrm{OBC}$.

Following Muller's experiment on justifying the ideal first $\mathrm{T}_{\mathrm{s}}($ Muller $A J$, et al. $J$ Therm Anal Calorim, 2000, 59, 451), we have conducted supplementary experiments to test the ideal first $\mathrm{T}_{\mathrm{s}}$. The sample as-received $\mathrm{OBC}$ was chosen as the testing sample. Firstly, the sample was heated to $200{ }^{\circ} \mathrm{C}$ at a rate of $30^{\circ} \mathrm{C} / \mathrm{min}$ and kept at $200{ }^{\circ} \mathrm{C}$ for $5 \mathrm{~min}$ to erase thermal history. Secondly, the sample was cooled to $25{ }^{\circ} \mathrm{C}$ at a rate of $10{ }^{\circ} \mathrm{C} / \mathrm{min}$ to create the initial "standard" state. Thirdly, the crystallized sample was heated to the chosen first $\mathrm{T}_{\mathrm{s}}$ at a rate of $10{ }^{\circ} \mathrm{C} / \mathrm{min}$ and kept at that temperature for $5 \mathrm{~min}$ to undergo self-nucleation. The chosen $\mathrm{T}_{\mathrm{s}}$ ranged from $100{ }^{\circ} \mathrm{C}$ to $130{ }^{\circ} \mathrm{C}$ at an interval of $1{ }^{\circ} \mathrm{C}$. Fourthly, the sample was subsequently cooled at $10{ }^{\circ} \mathrm{C} / \mathrm{min}$ from $\mathrm{T}_{\mathrm{s}}$ down to the chosen minimum temperature $25{ }^{\circ} \mathrm{C}$ and the crystallization curves during cooling were recorded. Finally, subsequent heating at $10{ }^{\circ} \mathrm{C} / \mathrm{min}$ was conducted from the chosen minimum temperature up to the maximum melting temperature and the melting curves were also recorded. The crystalline and melting curves after self-nucleation of as received $\mathrm{OBC}$ at each $\mathrm{T}_{\mathrm{s}}$ are shown in Figure S2a and 2b, respectively. 
Fillon et al. (Fillon B, et al. J Polym Sci B, 1993, 31, 1383) have defined the so-called domains of self-nucleation for PP and we shall use their nomenclature here. We can conclude from the Figure $\mathrm{S} 2$ that at $127^{\circ} \mathrm{C}$ OBC is self-nucleated by remanent crystal fragments and crystallization temperature shifts to higher temperatures while the subsequent melting does not reveal any traces of annealing. This is a characteristic behavior of domain II (i.e., only self-nucleation) and the typical behavior is found only in the range of $127-123{ }^{\circ} \mathrm{C}$. Temperatures below or equal to 122 ${ }^{\circ} \mathrm{C}$ produces self-nucleation and annealing, i.e. samples in domain III, and the high temperature melting peaks on the melting curves are due to annealing. The characteristic behavior of the selfnucleation of $\mathrm{OBC}$ presented in Figure $\mathrm{S} 2$ indicates that the maximum temperature that induces self-nucleation without any annealing, or the minimum temperature of domain II is $123^{\circ} \mathrm{C}$. In Muller's opinion, the ideal first $\mathrm{T}_{\mathrm{s}}$ should be high enough to melt most of the polymer, but low enough to leave some crystal fragments that can act as nuclei but will not anneal during the 5 min at that $\mathrm{T}_{\mathrm{s}}$. Therefore, we choose $123{ }^{\circ} \mathrm{C}$ as the optimum first $\mathrm{T}_{\mathrm{s}}$ for $\mathrm{OBC}$ in our work. 


\section{Calculation of the equilibrium melting point of OBC}

(a)

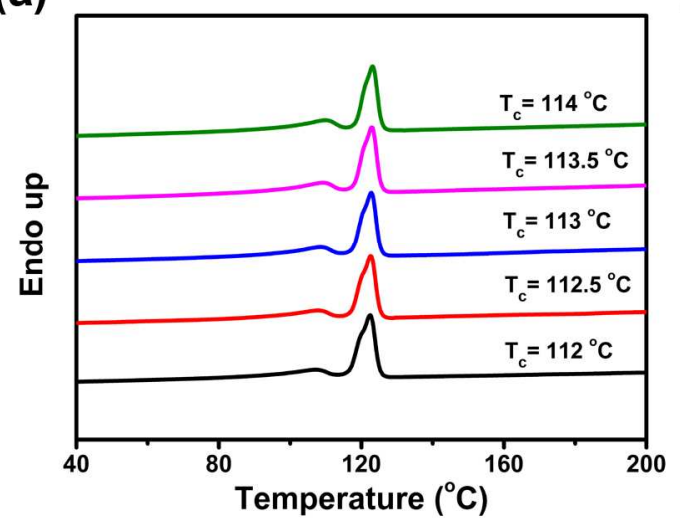

(b)

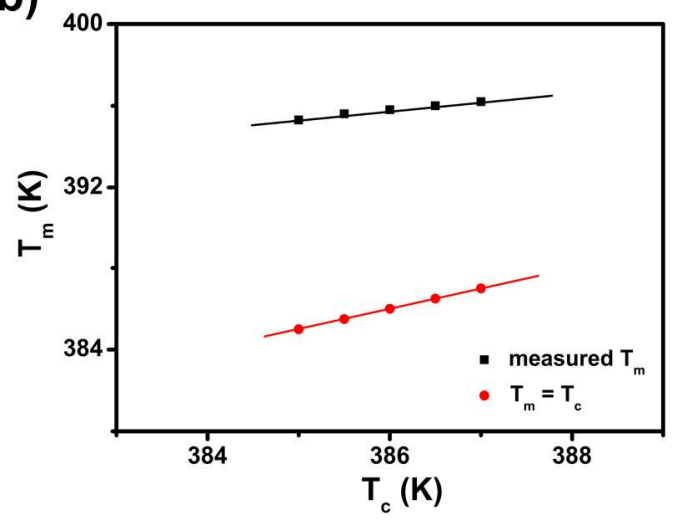

Figure S3. DSC melting curves of as received $\mathrm{OBC}$ after isothermal crystallization at $\mathrm{T}_{\mathrm{c}} \mathrm{S}$ (a) and linear fitting of $\mathrm{T}_{\mathrm{m}} \mathrm{s}$ of as received $\mathrm{OBC}$ after isothermal crystallization with $\mathrm{T}_{\mathrm{c}} \mathrm{s}$ of isothermal crystallization (b).

The equilibrium melting point $\left(\mathrm{T}_{\mathrm{m}}{ }^{0}\right)$ of $\mathrm{OBC}$ is the crossover point of the fitted line of $\mathrm{T}_{\mathrm{m}} \mathrm{s}$ with $\mathrm{T}_{\mathrm{c}} \mathrm{s}$ isothermal crystallization experiments and the line of $\mathrm{T}_{\mathrm{m}}=\mathrm{T}_{\mathrm{c}}$ (Hoffman, J. D., Weeks, J. J. J. Res. Natl. Bur. Std., 1962, Set. A, 66A.). The $\mathrm{T}_{\mathrm{m}} \mathrm{s}$ of $\mathrm{OBC}$ crystallized at $\mathrm{T}_{\mathrm{c}}=112,112.5,113$, 113.5 and $114{ }^{\circ} \mathrm{C}$ are $123.3,123.6,123.8,123.0$ and $124.2^{\circ} \mathrm{C}$, respectively. The $\mathrm{T}_{\mathrm{m}}{ }^{0}$ of $\mathrm{OBC}$ was calculated to be $130.5^{\circ} \mathrm{C}$. 